\title{
Uma solução para a medição de vazão de esgoto em estações elevatórias
}

\section{A simple method to measure sewage water in pumping stations}

Data de entrada: $18 / 09 / 2014$

- Data de aprovação: $14 / 04 / 2016$

Marcos Tadeu Pereira, Nilson Massami Taira

DOI: 10.4322/dae.2016.022

\section{Resumo}

O artigo apresenta o desenvolvimento de medidor de vazão do tipo cotovelo para a medição de vazão em estações elevatórias de esgoto. São descritos os resultados de ensaios realizados em laboratório, a aplicação de um transdutor de pressão especial para a medição da diferença de força centrífuga entre as duas tomadas de pressão do cotovelo e, finalmente, os ensaios realizados em campo, em uma estação elevatória de esgoto. Os resultados permitem afirmar que para valores de números de Reynolds superiores a $10^{5}$, os valores do coeficiente $\mathrm{K}$ são constantes dentro de $\pm 1 \%$ e seguem a curva teórica dentro de $\pm 0,5 \%$. A incerteza de medição na vazão determinada em laboratório foi de $2 \%$.

Palavras-chave: medição de vazão, medidor tipo cotovelo, vazão de esgoto.

\section{Abstract}

The paper shows the development of an elbow flowmeter for the measurement of flow rate in sewage pumping facilities. The paper describes the results of laboratorial tests, the use of a special pressure transducer for the measurement of the difference in centrifugal force in the pressure taps of the elbow and, finally, the field tests in a sewage pumping facility. Results show that for Reynolds numbers greater than $10^{5}$ the $\mathrm{K}$ coefficients are constant within $\pm 1 \%$ and follow the theoretical curves within $\pm 0,5 \%$. The uncertainty in the measurement of the flow rate was determined to be better than $2 \%$.

Keywords: flow measurement, elbow flowmeter, sewage flow rate.

Marcos Tadeu Pereira, Doctor in Mechanical Engineering, Professor at the Polytechnic School of the University of São Paulo, marcospereiraa usp.br

Nilson Massami Taira, Master in Mechanical Engineering, researcher of IPT, nmtairaaipt.br

Endereço para correspondência: Escola Politécnica da Universidade de São Paulo, Departamento de Engenharia Mecânica. Avenida Professor Mello de Morais / Butantã cep: 05508030 - São Paulo, SP - Brasil. E-mail: marcospereiraausp.br 


\section{INTRODUÇÃO}

Dentre as atividades de medição, verificação e controle de variáveis de processos, a medição de vazão sempre apresentou grandes dificuldades, tanto do ponto de vista da teoria quanto da instalação e operação.

Estas dificuldades são facilmente exemplificadas pelos níveis de incerteza que podem ser obtidos: na medição de vazão ou de velocidades de fluidos, quando se atinge $1 \%$ ou $1,5 \%$, sabe-se que é um resultado excelente, pois raramente se conseguem valores melhores que estes. Em contrapartida, pode-se medir massa com incertezas de $0,0001 \%$, pressão e dimensões com níveis inferiores a $0,01 \%$ e $0,0001 \%$, respectivamente.

Por que o valor mais elevado da incerteza na medição de vazão? Alguns motivos básicos:

1. no escoamento dentro da tubulação, o efeito de distorção no perfil de velocidades médias na seção de medição, devido à topologia e singularidades da tubulação, é difícil de prever e é sempre impactante nos resultados;

2. o fenômeno da turbulência (presente nos escoamentos) é extremamente difícil de modelar, seu conhecimento ainda é precário e cobra sua cota de incerteza nos resultados de medição de vazão;

3. vazão é uma grandeza dinâmica (massa ou volume dividido pelo tempo) o que torna o uso de padrões primários difícil ou impossível, além de ser variável na escala de tempo.

A medição de vazão de esgoto em estações elevatórias por si só representa um desafio adicional: o fluido é difícil; as condições de operação são ruins (o bombeamento funciona de forma intermitente); a proximidade entre bomba e medidor de vazão introduz distorções de perfis de velocidade, turbulência adicional e pulsações (são bombas geralmente submersas, com poucas pás). Poucos medidores de vazão são adequados para esta situação.

O artigo descreverá o uso de um medidor bem antigo e pouco usado, que parece ser o ideal para esta situação: a medição em curva, ou medidor tipo cotovelo.

\section{AS DIFICULDADES PARA ESTUDAR ESCOAMENTOS NO INTERIOR DE TUBULAÇÕES}

Desde 1842, acredita-se que a solução dos escoamentos e fenômenos relacionados à Mecânica dos Fluidos seria dada pela equação de Navier-Stokes:

$\frac{\partial \mathrm{V}}{\partial \mathrm{t}}+\mathrm{V} \cdot \nabla \mathrm{V}=-\frac{1}{\rho} \nabla \mathrm{p}+v \nabla^{2} \mathrm{~V}$

onde:

$\mathrm{V}$ - velocidade média, em $\mathrm{m} / \mathrm{s}$

$t$ - tempo, em segundos

$\mathrm{p}$ - massa específica, em $\mathrm{kg} / \mathrm{m}^{3}$

$\rho$ - pressão, em Pascal

$v$ - viscosidade cinemática, em $\mathrm{m}^{2} / \mathrm{s}$

Apesar desta crença, mais de 170 anos se passaram, e ainda não se tem uma solução para esta equação, a não ser para escoamentos extremamente simples, como os laminares.

Se a velocidade na equação de N-S for substituída pela decomposição de velocidade proposta por Reynolds, $\mathrm{V}=\overline{\mathrm{V}}+\mathrm{v}$ ' (velocidade igual a valor médio mais flutuação de velocidade), são gerados termos de ordem superior para as componentes flutuantes, e estes termos são geralmente da mesma ordem de grandeza que os de ordem menor e não podem ser desprezados. Esta é uma equação diferencial parcial não linear e, segundo Warhaft ${ }^{(1)}$, neste aspecto as equações de $\mathrm{N}-\mathrm{S}$ são as mais intratáveis equações de campo que se conhecem, incluindo as da relatividade geral.

Warhaft ${ }^{(1)}$ continua: turbulência, conforme livros textos atuais, é irregular, tem vorticidade forte, causa mistura rápida e é um fenômeno multies- 
cala, ou seja, os "eddies" (o mais próximo em português seria "turbilhões", com alguma perda de significado) têm tamanhos diferentes.

Feynman escreveu nos anos 1960: "Finalmente, há um fenômeno físico que é comum em muitas áreas, é muito velho e ainda não foi resolvido [...] é $a$ análise de escoamentos turbulentos [...] A forma mais simples do problema é o escoamento de água em alta velocidade por um tubo longo. Pergunta-se: para bombear certa quantidade de água neste tubo, quanta pressão é necessária? Ninguém pode analisar isto a partir dos primeiros princípios e das propriedades da água. Se a água escoar lentamente, ou se for usada uma substância viscosa como mel, então nós podemos fazer isso com certafacilidade, como se vê inclusive em livros textos de graduação. 0 que não podemos ainda fazer é tratar com água real escoando em um duto. Este é o problema central que teremos que resolver, um dia, e ainda não conseguimos."

Esta observação de Feynman, um dos mais criativos e competentes físicos (e prêmio Nobel) do século $X X$, continua válida nos dias de hoje, e é surpreendente em sua simplicidade ao colocar o problema: grande avanço científico e tecnológico, mecânica quântica, teoria da relatividade, etc., e um problema tão simples, banal e presente na vida de todos, (como o escoamento turbulento em um duto) não consegue ser resolvido, do ponto de vista dos físicos e matemáticos, a partir dos princípios básicos.

Como não se dispõe de uma solução teórica de campo da equação de Navier-Stokes, resta a via experimental, de observação da física do processo.

Ainda segundo Warhaft ${ }^{(1)}$, da observação de fenômenos é aparente que as escalas maiores de turbulência dependem da forma em que o escoamento turbulento é formado, ou seja, os escoamentos num tubo reto como uma chaminé, numa superfície plana ou numa curva como um cotovelo, são diferentes em suas escalas maiores, visíveis e, portanto, definitivamente estas escalas maio- res não são universais. As escalas maiores caracterizam o escoamento.

Mas, e se forem olhadas as escalas menores de turbulência? Seria possível que a turbulência possa parecer a mesma? O conhecimento atual sobre turbulência parece indicar que este é o caso, conforme Kolmogorov, que em 1941 postulou que há uma cascata de energia turbulenta dos "eddies" (vórtices) maiores para os menores. A taxa de entrada de energia (por unidade de massa) nas escalas maiores neste modelo seria igual ao fluxo de energia das escalas maiores para as menores.

Os estudos teóricos realizados por físicos e matemáticos ainda não permitiram "resolver" a turbulência, apesar da grande quantidade de modelos que surgiram nas duas últimas décadas.

Já os engenheiros resolveram na "força bruta", ou seja, fizeram experimentos, derivaram coeficientes para fazer algumas correções de rumo, e resolvem os problemas que aparecem da melhor maneira possível, dentro das limitações existentes.

A turbulência de grande escala provavelmente é única para cada configuração de cotovelo, conforme adiantado anteriormente. E como a abordagem será experimental, sempre se terá que ensaiar um conjunto de cotovelos, com diferenças entre si, para que se possam levantar os coeficientes adequados. Isto implica que o estudo experimental é o que resta para a determinação dos coeficientes de vazão de um medidor como o cotovelo.

\section{O COTOVELO DE MEDIÇÃO}

O problema colocado é a medição de vazão em um sistema de bombeamento em estações elevatórias de esgoto. Estas estações elevatórias seguem geralmente um padrão de projeto, em um poço de concreto, sistemas de separação de sólidos e areia, bomba submersa com rotor com duas pás no impelidor, elevação por meio de tubulação com 4 a 7 metros de comprimento na vertical, seguida 
de uma curva (cotovelo) a $90^{\circ}$, conectada por sua vez a outra tubulação.

Com este lay-out, instalar um medidor de vazão no trecho reto apresenta problemas: se for um medidor de inserção, provocaria perda de carga adicional e provavelmente estaria a uma distância muito curta em relação à bomba, e geraria erros adicionais de grande magnitude; se for medidor instalado externamente, não intrusivo, como o fluido é complicado, certamente virá com muitos vórtices, turbilhões e perfis de velocidade bastante deformados, devido à proximidade e tipo da bomba, o que implicaria o surgimento de erros de difícil contabilização.

A alternativa pensada foi a utilização de um medidor pouco usado, esquecido, mas que seria talvez o ideal para esta situação: o medidor de vazão do tipo cotovelo.

A literatura ${ }^{(2),(3),(4),(5),(6),(7),(8),(9),(10),(11),(12) ~ d i s p o n i ́ v e l ~ s o-~}$ bre cotovelos inicia-se na década de 1910, mas é reduzida e não permite conclusões definitivas sobre seu uso dentro de faixas de incertezas aceitáveis tecnologicamente.

Como uma abordagem teórica está fora de questão, dadas as dificuldades expostas anteriormente, decidiu-se por uma abordagem de engenharia: ensaios em laboratório e em campo, acompanhados do levantamento de coeficientes por comparação com outros princípios de medição.

Este tipo de medidor de vazão, implementado em um cotovelo, depende do diferencial de pressão existente entre tomadas de pressão instaladas nos raios de curvatura externos e internos da curva.

A Figura 1 mostra o desenho de um medidor tipo cotovelo.

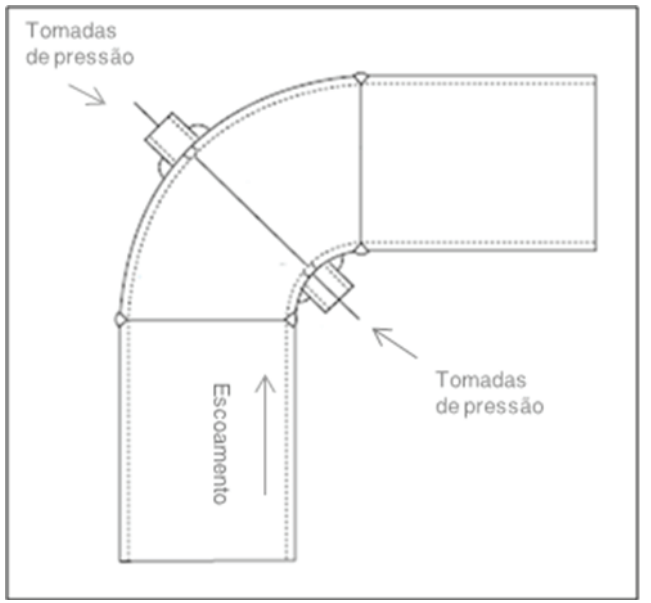

Figura 1 Esquema de um medidor de vazão tipo cotovelo

Estas diferenças de pressão são causadas pela força centrífuga que resulta das mudanças de direção do fluido se movimentando na tubulação em curva, que é um mecanismo diferente do mecanismo de perda de carga introduzida por uma placa de orifício inserida em uma tubulação. $\mathrm{Na}$ placa de orifício, o mecanismo está baseado efetivamente na "perda" (o termo correto seria transformação) de energia provocada pela singularidade. As equações para as duas situações são formalmente muito parecidas, como se verá.

A equação 2 mostra o cálculo de vazão volumétrica utilizando uma placa de orifício:

$Q=\frac{C}{\sqrt{1-\beta^{4}}} \cdot \varepsilon \cdot \frac{\pi}{4} \cdot d^{2} \cdot \sqrt{\frac{2 \Delta p}{\rho}}$

onde:

$\mathrm{Q}$ - vazão volumétrica, em $\mathrm{m}^{3} / \mathrm{s}$

$\mathrm{C}$ - coeficiente de descarga

$\beta$ - relação de áreas (diâmetro do orifício sobre diâmetro do duto), adimensional

$\varepsilon$ - fator de expansão, adimensional

d - diâmetro do orifício, em metros

$\Delta \mathrm{p}$ - diferença de pressão na placa, em Pascal

$\rho$ - massa específica, em $\mathrm{kg} / \mathrm{m}^{3}$ 
A letra $C$ representa o coeficiente de descarga da placa, que é função das dimensões da placa e duto, do tipo de tomada de pressão, da rugosidade e do número de Reynolds, e serve para corrigir o desconhecimento teórico que se tem do fenômeno.

Os valores de $\mathrm{C}$ foram levantados em milhares de ensaios nas últimas décadas, sendo apresentados em normas como a NBR-ISO 5167, com centenas de páginas restringindo e condicionando duramente as condições de utilização, geometria, rugosidade, números de Reynolds, etc. Isto não está disponível para cotovelos.

A equação 3 mostra o cálculo de vazão volumétrica utilizando a diferença de pressão entre os lados externo e interno do cotovelo, onde o que comanda o fenômeno é a força centrífuga.

$Q=K \frac{\pi}{4} \cdot D^{2} \cdot \sqrt{\frac{2 \Delta p}{\rho}}$

onde:

$\mathrm{K}$ - coeficiente de vazão, adimensional, para cotovelos

D - diâmetro da tubulação, em metros.

Segundo Lipták ${ }^{(12)}$ o valor de K para tomadas a $45^{\circ}$, calculado por Murdock ${ }^{(7)}$, é dado por:

$K=\sqrt{\frac{r_{b}}{2 D}} \cdot\left(1+\frac{6,5}{\sqrt{R e_{D}}}\right) \pm 4 \%$

quando se usam unidades coerentes, com o número de Reynolds da tubulação acima de $10^{4} \mathrm{e}$ com $r_{b} / D>1,25$. $O$ segundo termo da equação é desprezível acima de $10^{6}$.

onde:

$\mathrm{r}_{\mathrm{b}}$ - raio de curvatura do cotovelo em metros,

$\mathrm{Re}_{\mathrm{D}}$ - número de Reynolds do escoamento do fluido.

Ainda segundo Lipták, para números de Reynolds acima de $10^{5}$, a equação acima pode ser reduzida a:
$K=0,98 \cdot \sqrt{\frac{r_{b}}{2 D}} \pm 6 \%$

Deve-se ter em mente que esta equação foi baseada em uma amostra limitada de ensaios realizados por Murdock.

Lipták ${ }^{(12)}$ deixa claro que o coeficiente $K$ de um medidor tipo cotovelo é geralmente confiável dentro de 5 a 10\%, mas "não existem dados suficientes para estabelecer fatores de correção precisos para os efeitos de perturbações a montante, viscosidade, rugosidade na tubulação e no cotovelo".

Ainda não há estudos que possam ser acessados e que correlacionem $K$ com o número de Reynolds para aplicações especiais como a de medição de esgoto.

Para suprir esta lacuna de dados, a Sabesp solicitou ao IPT a definição de um modelo de medidor e deu suporte à realização de ensaios em laboratório e em campo.

\section{OS ENSAIOS LABORATORIAIS}

Para o levantamento de dados foram realizados ensaios em um cotovelo de $90^{\circ}$, previamente em uso na Sabesp, com tomadas de pressão a $22,5^{\circ} \mathrm{e}$ a $45^{\circ}$. A figura seguinte mostra o arranjo experimental no laboratório do IPT.

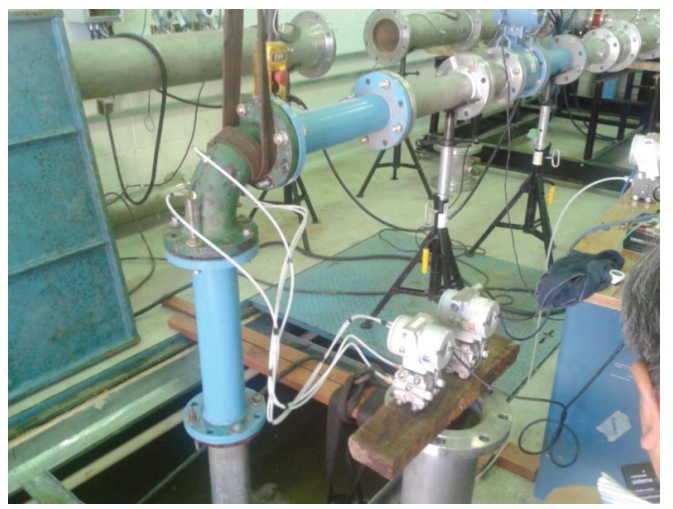

Figura 2. Arranjo experimental no Laboratório de Fluidodinâmica do IPT. A bomba submersa recalca água para a tubulação vertical, passa pelo cotovelo (com duas tomadas de pressão) e segue na horizontal, passando pelo medidor de vazão eletromagnético. 

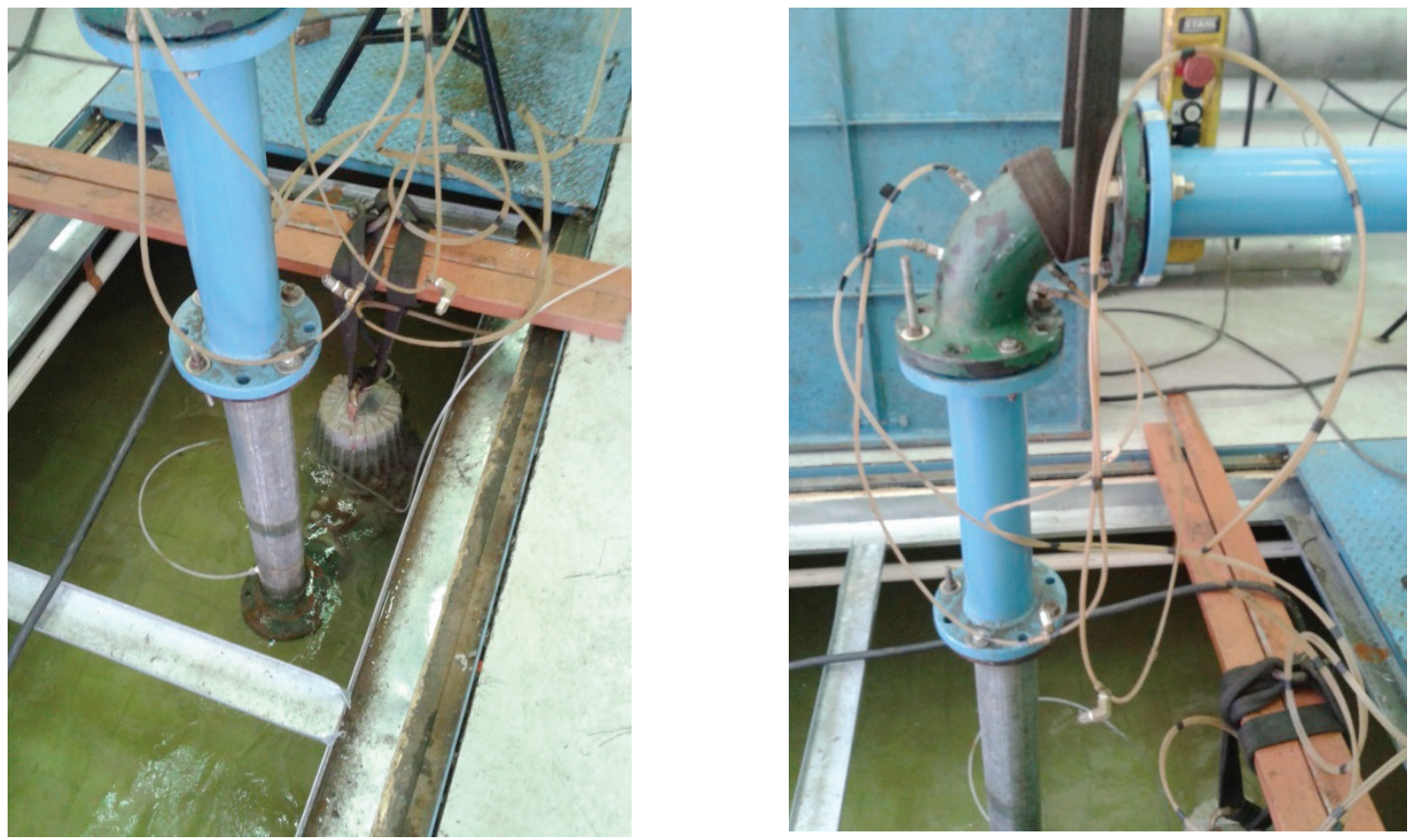

Figura 3. A foto da esquerda mostra a posição da bomba. A foto da direita mostra o cotovelo com as tomadas de pressão a $22,5^{\circ}$ e a $45^{\circ}$.
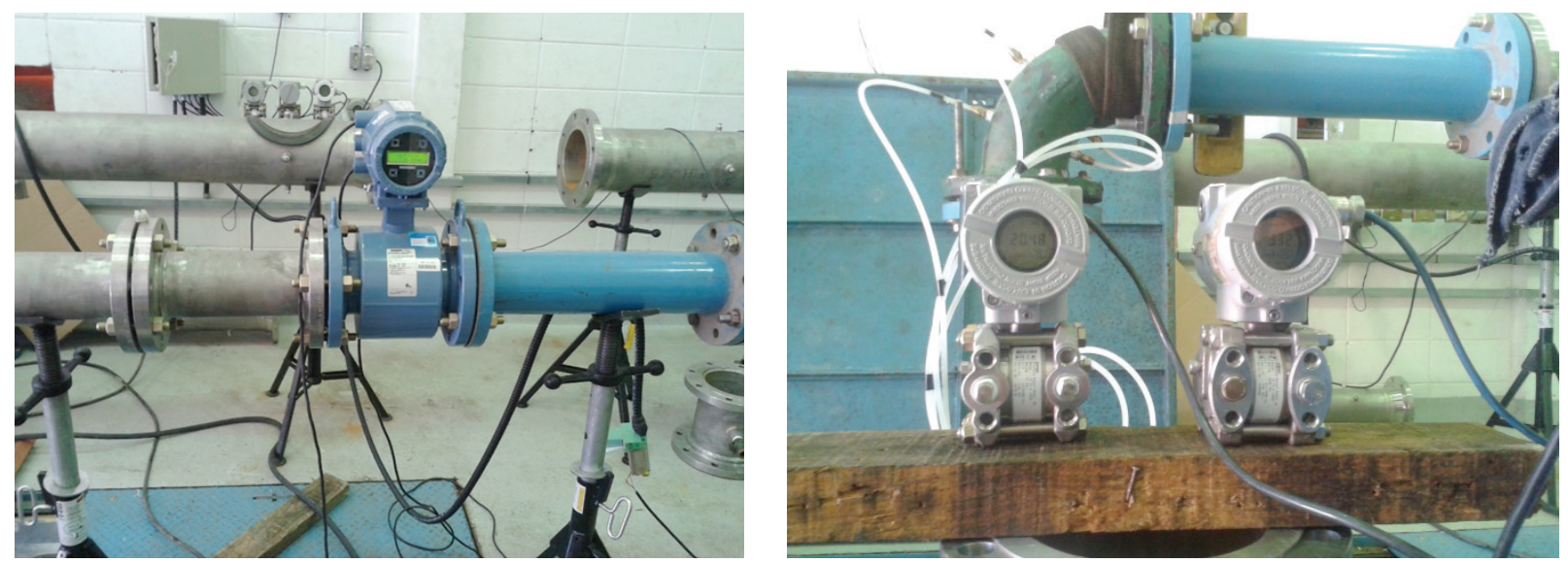

Figura 4. Medidor de vazão de referência eletromagnético e transdutores de pressão capacitivos.

Para a realização desta atividade, a SABESP enviou uma bomba submersível com $10 \mathrm{cv}$ de potência máxima, (380/220V 1735 rpm), conforme mostra a Figura 3, e trechos de tubulação para a montagem nas instalações do IPT. 

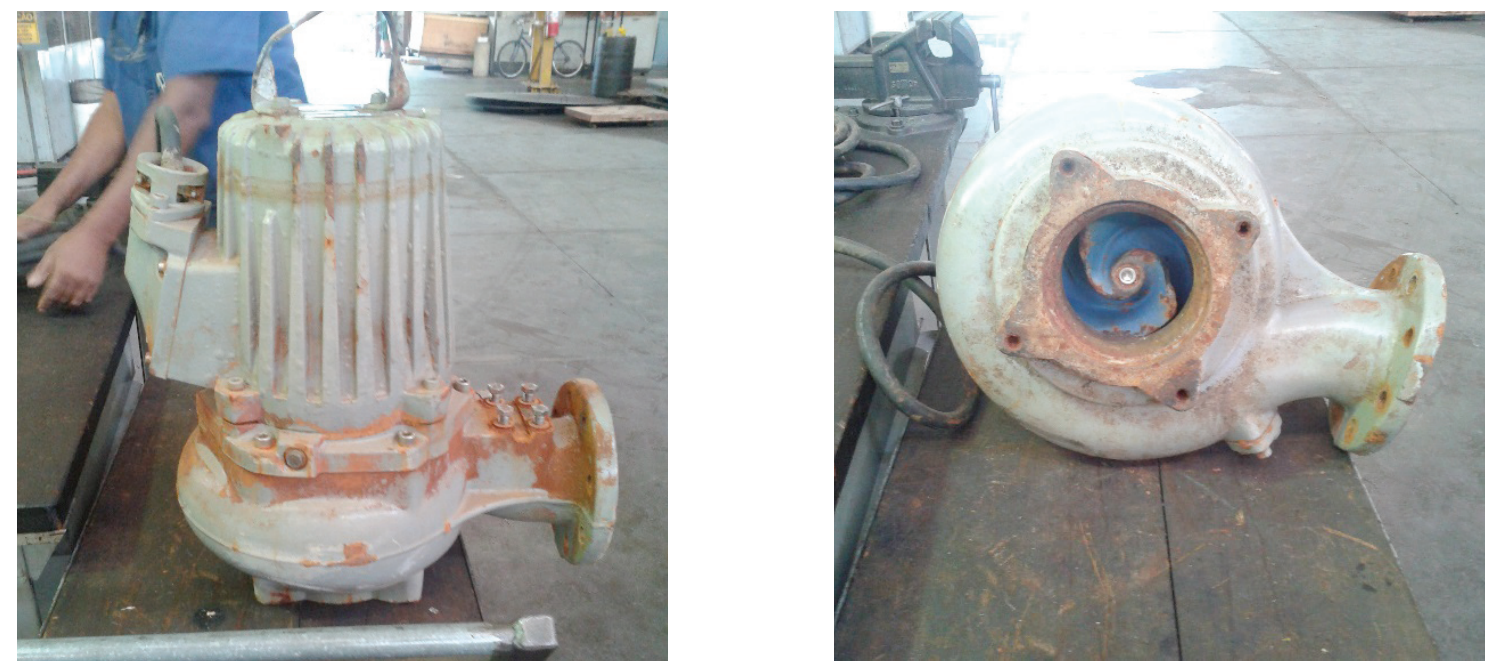

Figura 5. Bomba utilizada nos ensaios em laboratório e em campo.

A bomba foi ensaiada no IPT para o levantamento das curvas características, mostradas na Figura 6. Foi medida a pressão estática na saída da bomba com um transdutor manométrico capacitivo, e foram medidas ainda a vazão com um medidor de vazão eletromagnético de 4" de diâmetro, e as variáveis elétricas (tensão, corrente e potência) de alimentação do motor da bomba.

Figura 6. Curvas características da bomba. Os termos subida e descida representam medições tomadas no sentido da elevação ou diminuição da vazão.

As curvas da bomba, levantadas em laboratório, serviram para que, no ensaio em campo, fossem conferidos os valores de vazão em função das variáveis elétricas.

Para desenvolver a metodologia de medição por cotovelo, foram utilizados transdutores de pressão diferenciais capacitivos, que necessitam de mangueiras para transmissão do sinal de pressão desde a tomada de pressão no cotovelo até a posição em que os transdutores estão alojados e nivelados.
Foram instaladas duas tomadas de pressão diferencial no cotovelo: uma a $45^{\circ}$ e a outra a $22,5^{\circ}$, que são duas posições mencionadas na literatura. No ensaio foi utilizada uma válvula para controlar a vazão do sistema nos pontos de interesse para o levantamento das curvas características da bomba e do coeficiente de vazão do cotovelo.

Toda a tubulação era mantida afogada durante os ensaios, para evitar problemas de entrada de ar no circuito, o que, se ocorresse, ocasionaria perda de qualidade nas medições.

\section{RESULTADOS DOS ENSAIOS DO COTOVELO}

Nos ensaios foram coletados todos os dados necessários para os cálculos do coeficiente de vazão do cotovelo. Os ensaios foram realizados subindo a vazão ponto a ponto e, depois, descendo a vazão, ponto a ponto.

Para interpretar os dados, foi calculado o valor teórico do coeficiente de descarga do cotovelo, como definido na equação (4), agora considerando o valor de K como "K teórico".

Foram então calculados os valores de $\mathrm{K}_{\text {referência: }}$ 


$$
K_{\text {referência }}=\frac{Q}{\frac{\pi}{4} \cdot D^{2} \cdot \sqrt{\frac{2 \Delta p}{\rho}}} \quad \text { (6) } \quad \begin{aligned}
& \text { Desvio }=\mid K_{\text {teórico }}-K_{\text {referência } \mid} \text { (7) } \\
& \text { Desvio relativo }=\frac{\left|K_{\text {teórico }}-K_{\text {referência }}\right|}{K_{\text {teórico }}} .100
\end{aligned}
$$

Com os valores de $\mathrm{K}_{\text {teórico }}$ e $\mathrm{K}_{\text {referênncia }}$ foram então calculados os desvios absolutos e relativos entre eles:

Estes valores foram calculados, e foi construída a Figura 7.

\section{Constante de Vazão K \& Desvio Percentual - K34}

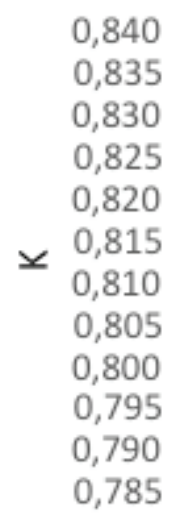

0,785
0

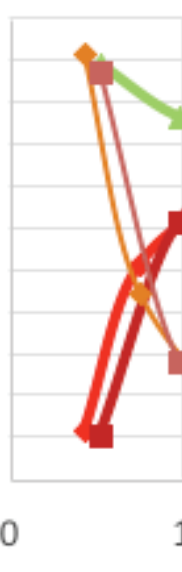

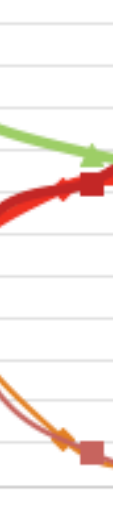

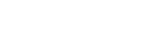

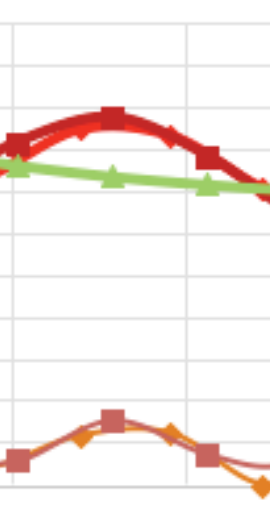

2
3

4
$6,00 \%$

$5,00 \%$

$4,00 \%$

$3,00 \%$

$2,00 \%$

$1,00 \%$

$0,00 \%$

Reynolds $\times 10^{5}$

\section{K34 - Subida}

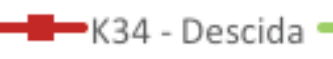

- Kteórico

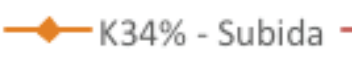

K34\% - Descida

Figura 7 - Comparação dos valores dos coeficientes teórico e real, para tomadas a $45^{\circ}$. Como se pode observar, para

valores de números de Reynolds superiores a $10^{5}$, os valores de $\mathrm{K}_{\text {teórico }}$ são constantes dentro de $\pm 1 \%$ para tomadas pressão a $45^{\circ}$ (e dentro de $\pm 3 \%$, para tomadas de pressão a 22,5\%, não mostradas na figura). Adicionalmente, tomadas de pressão a $45^{\circ}$ seguem a curva teórica dentro de $\pm 0,5 \%$.

O resultado a $45^{\circ}$ mostra que será possível usar esta configuração para ensaios em estações elevatórias de esgoto.

\section{MODIFICAÇÃO NO TRANSDUTOR DE PRESSÃO.}

Em laboratório, os ensaios mostraram que o método para a determinação de vazão por cotovelo era bastante repetitivo e com incerteza baixa, além de ser muito simples e de fácil instalação em campo.

Foram utilizados inicialmente transdutores de pressão capacitivos, que precisam ser ligados por uma linha de pressão que faz a transmissão da pressão entre a tomada de pressão na tubulação e o corpo do transdutor. No corpo do transdutor o fluido é acomodado em uma câmara, onde nas paredes existe uma membrana que é ligeiramente deformada com variações de pressão, e esta deformação gera um sinal elétrico que é proporcional à pressão aplicada.

O problema de se usar um transdutor deste tipo com um fluido multifásico e sujo, como é o esgoto, é a certeza de provocar falsas medições, que ocorrem por dois motivos principais:

a câmara do transdutor sempre deve ficar repleta de líquido, sem bolhas de ar, o que só é conse- 
guido ao pressurizar a linha de pressão e purgar a câmara do sensor. A purga de esgoto pode levar material estranho a se depositar na câmara, e teria que ser feita constantemente, dado o regime de intermitência com que a bomba funciona. Seria inviável fazer esta purga, pois a tubulação pode sofrer ciclos de esvaziamento/enchimento a cada 20 minutos, por exemplo. Adicionalmente, as condições de instalação podem não permitir fácil acesso para estas manobras constantes.

A tomada de pressão na tubulação, com dimensões reduzidas, seria inevitavelmente obstruída por detritos e depósitos, inviabilizando a medição.

Com o uso de um transdutor piezorresistivo sem câmara de medição ligada a mangueiras, estes problemas seriam eliminados, pois a membrana de medição é instalada faceando a superfície interna do cotovelo.

Com isto em mente, foi comprado um sensor piezorresistivo do tipo OEM (original equipment manufacturer), que foi preparado e testado em ensaios em laboratório e demonstrou ser de operação muito fácil, eliminando completamente a necessidade de purga, e mostrando características adequadas de repetitividade e incertezas, sem
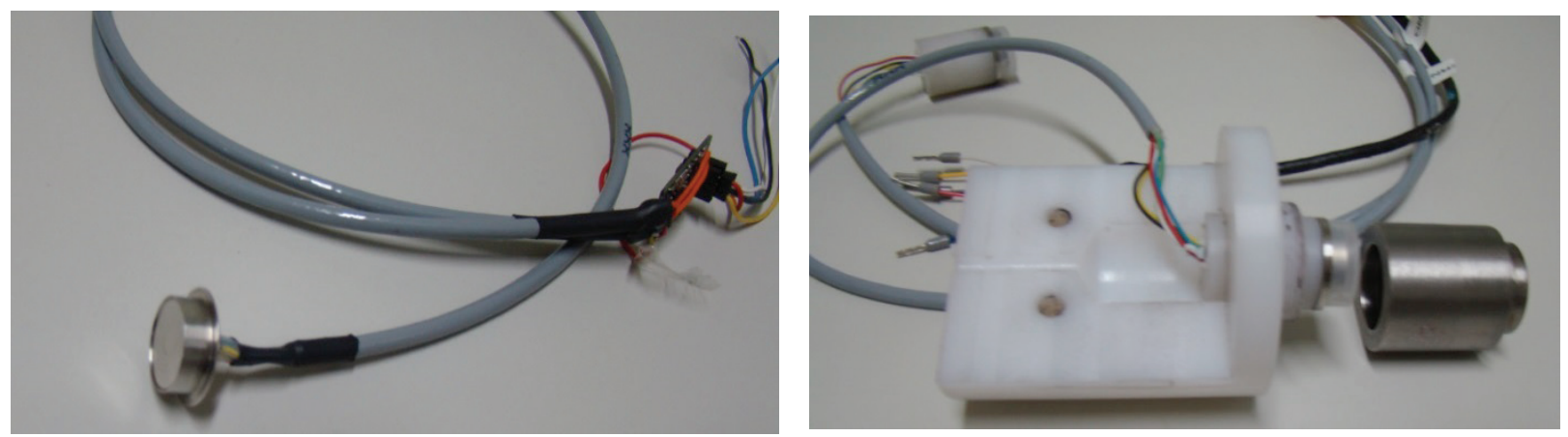

nada a perder nestes aspectos para os transdutores capacitivos.

Os resultados foram então trabalhados e consolidados, mostrando a resposta do método ao sistema proposto.

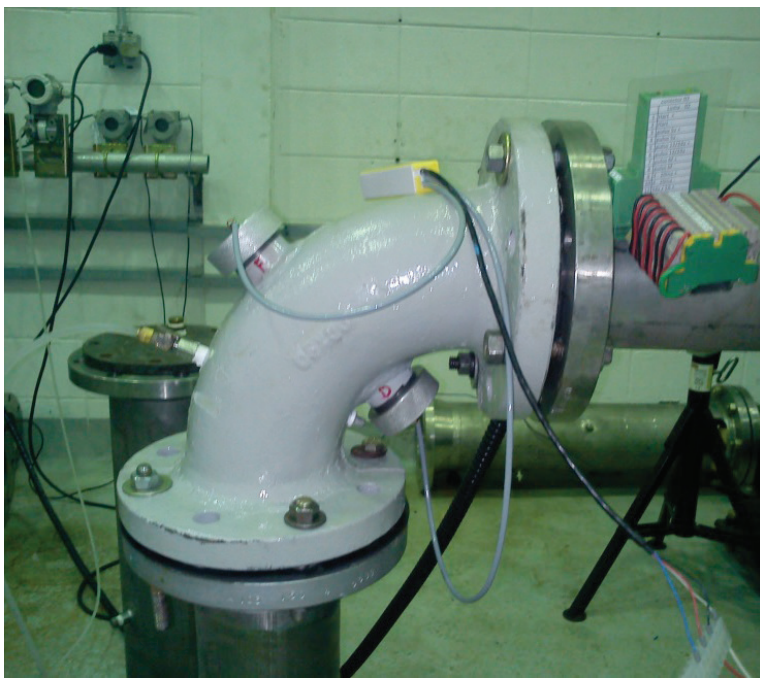

Figura 8 - Vista lateral do transmissor piezorresistivo instalado em laboratório. Observar que não há linha de pressão para transmitir pressão desde a tomada de pressão na tubulação até o sensor de pressão.

A próxima figura ilustra os dispositivos que foram construídos para a adaptação ao cotovelo dos novos transdutores de pressão piezométricos.

Figura 9 - Sensor OEM, como recebido da fábrica e montagem experimental para instalação em campo. 


\section{INSTALAÇÃO EM CAMPO}

A fase seguinte foi a verificação do comportamento do medidor em campo, na estação elevatória mostrada na Figura 13.

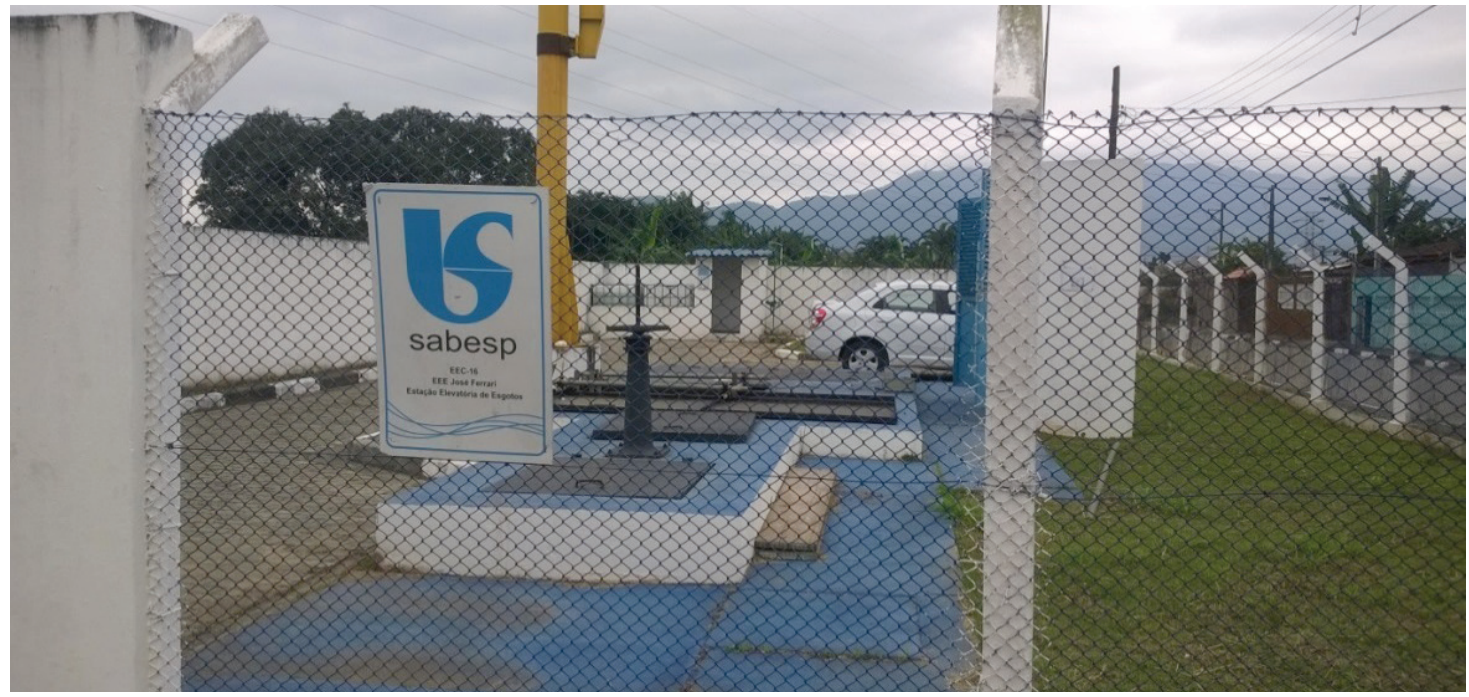

Figura 10 - Entrada da Estação Elevatória EEC 16 - EEE José Ferrari, em Caraguatatuba, onde foram realizados os ensaios em campo.

As fotos a seguir mostram o processo de instalação em campo do cotovelo, previamente ensaiado em laboratório, e a instalação do sensor piezorresistivo instalado com os dispositivos manufaturados para encapsular o sensor OEM.
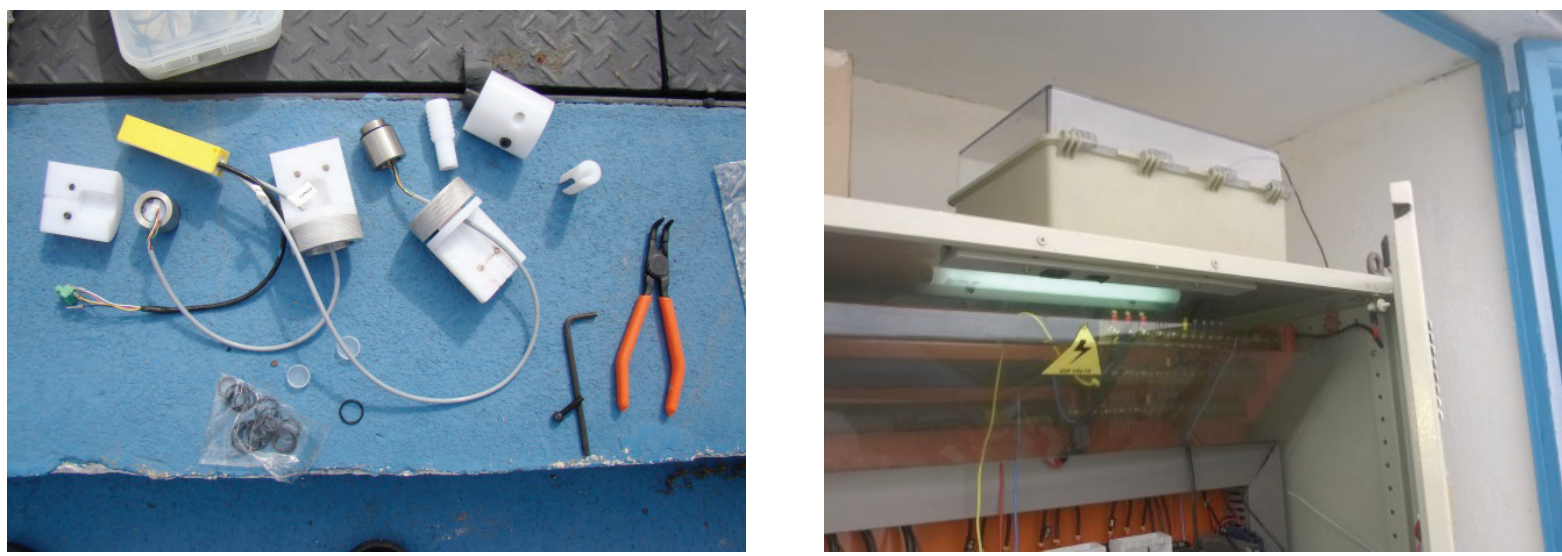

Figura 11 - A foto da esquerda mostra os sensores OEM desmontados e os dispositivos construídos para seu isolamento. Os sensores e a caixa de ligação (amarela) já estavam aparentemente isolados com silicone. A figura da esquerda mostra a caixa com o sistema de datalogger e baterias, encarregados da aquisição de sinais, colocada no gabinete elétrico das bombas. 

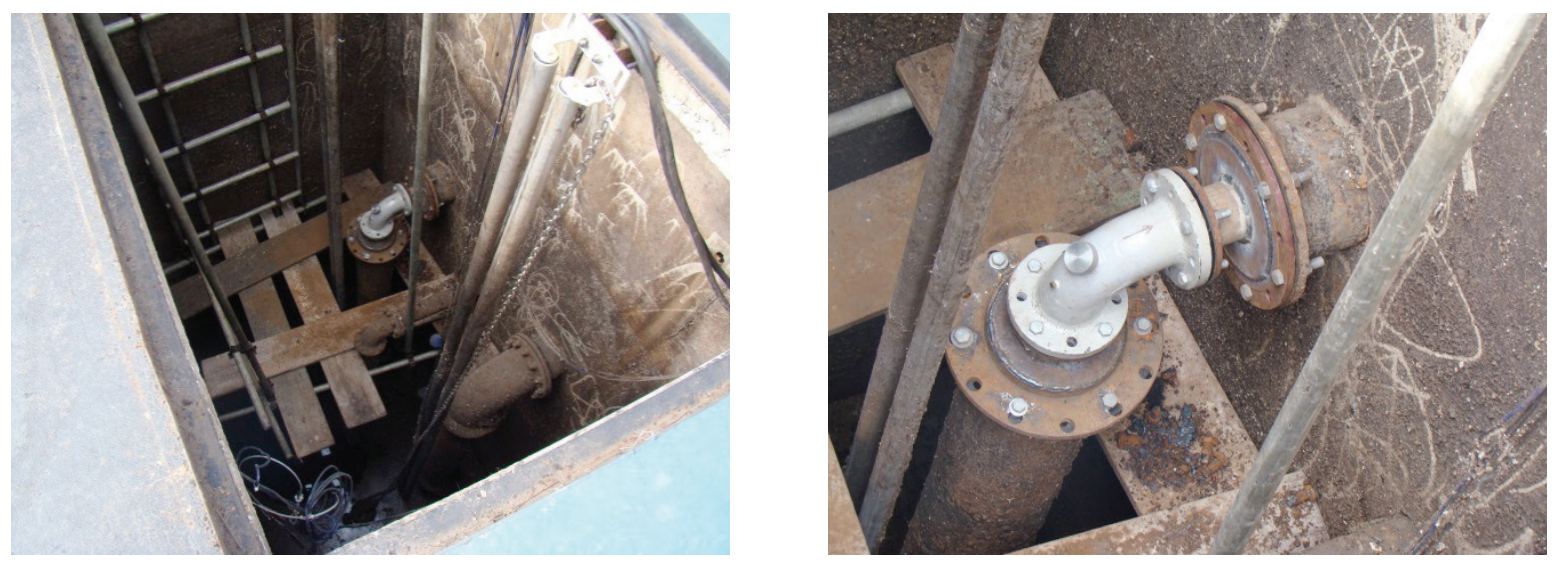

Figura 12 - A foto da esquerda mostra o poço de bombeamento da estação elevatória com o cotovelo já instalado. Observar a plataforma necessária para os trabalhos. A foto da direita mostra um detalhe do flange cego instalado na tomada de pressão durante a montagem.
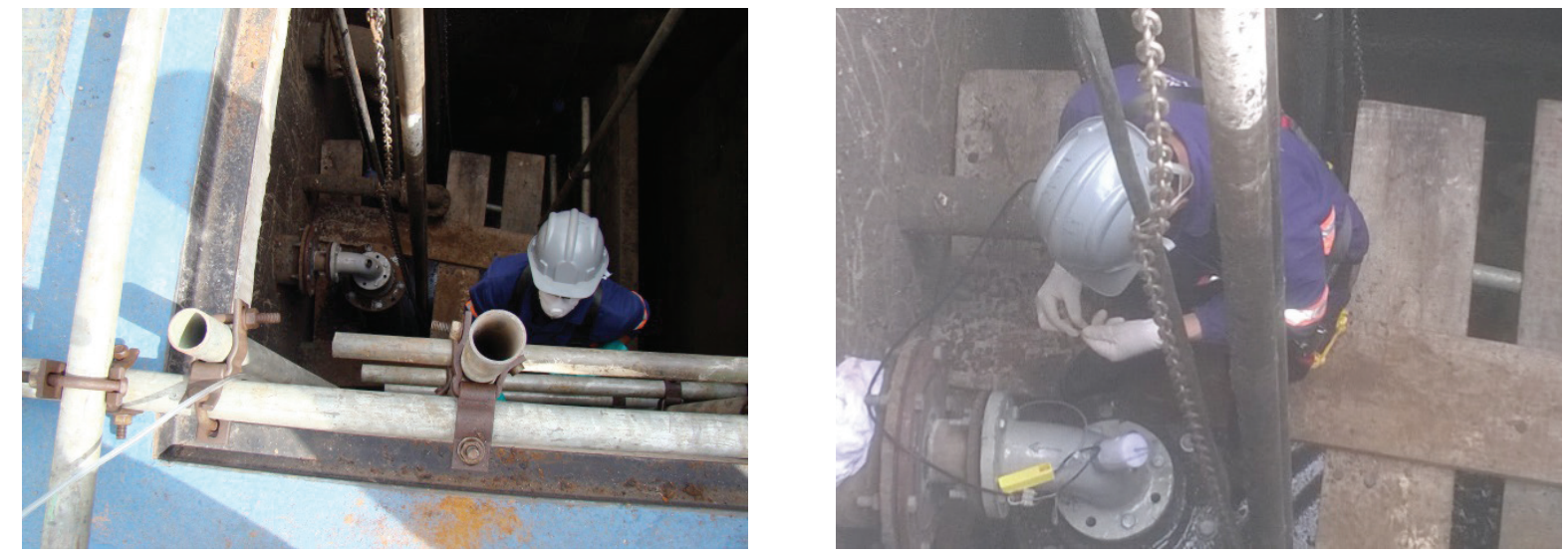

Figura 13 - A foto da esquerda mostra o cotovelo já sem o flange cego da tomada de pressão e a foto da direita mostra a instalação do sensor piezorresistivo.

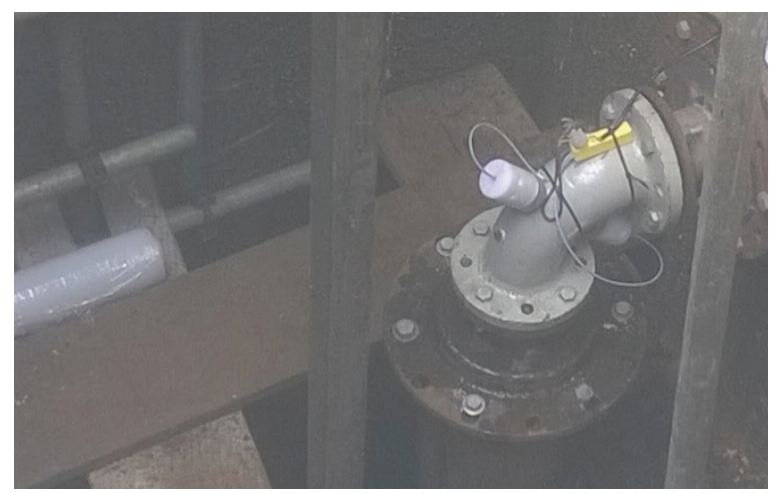

Figura 14 - A foto mostra o sensor já instalado no local. 
Esta configuração com o sensor piezorresistivo forneceu sinal no período compreendido entre $12 \mathrm{~h}$ do dia 5 de junho de 2014 até as $12 \mathrm{~h}$ do dia 9 de junho, quando o sensor parou de funcionar, devido a uma pane elétrica.

Foram então instalados transdutores de pressão capacitivos, num arranjo especial adaptado para que não houvesse interrupção dos ensaios.

\section{ENSAIOS EM CAMPO COM TRANSDUTORES PIEZORRESISTIVOS}

A Figura 15 mostra os registros completos da tensão do sinal elétrico de saída em função do tempo, obtidos a partir das medições em campo com o transdutor piezorresistivo, para o dia 7 de junho. Este registro de um dia de sinal mostra claramente os diversos ciclos de acionamento da bomba, com intervalos mais longos à noite e intervalos de duração aproximadamente igual durante o dia.

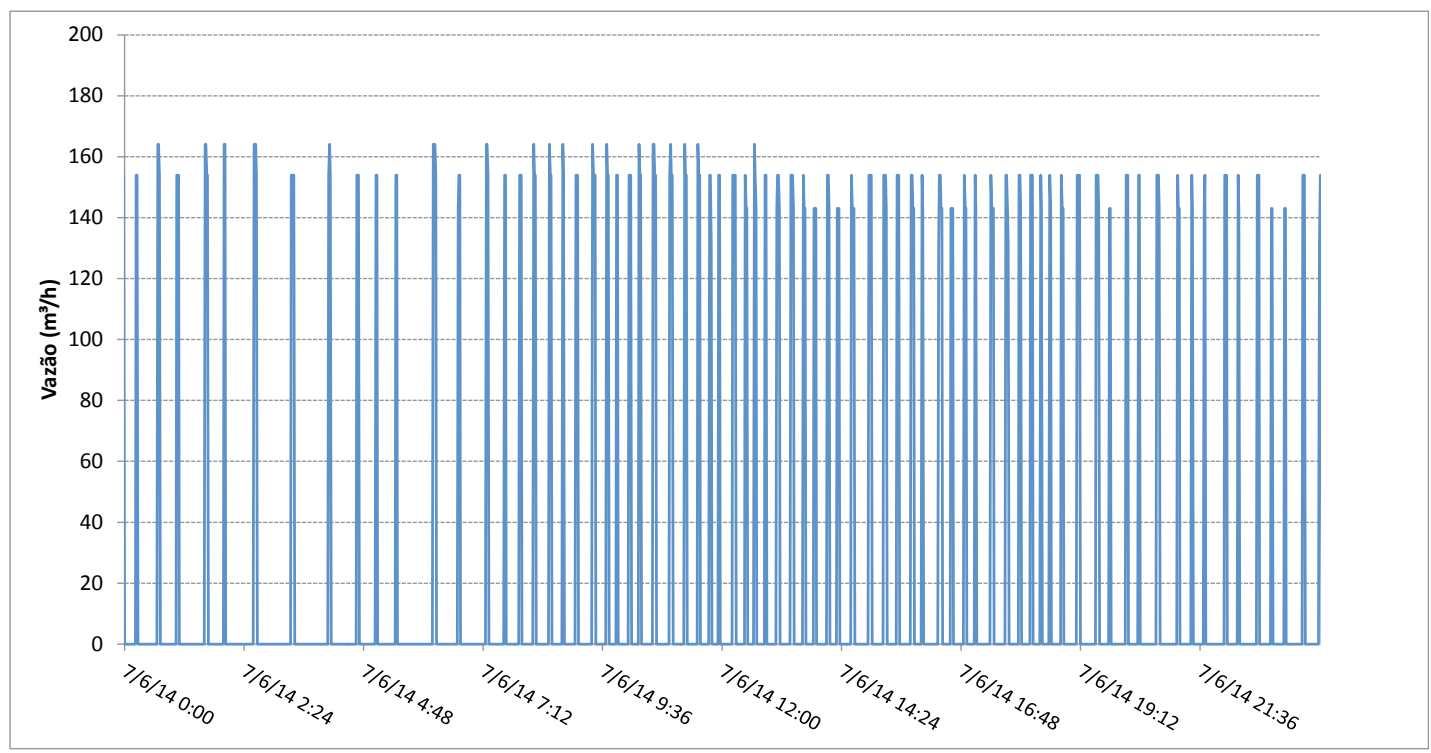

Figura 15 -A figura mostra um trecho entre as 0 h e as $24 \mathrm{~h}$ do dia 7 de junho, para exemplificar o tipo de sinal existente. O sinal já foi convertido de tensão para vazão. Transdutor piezorresistivo.

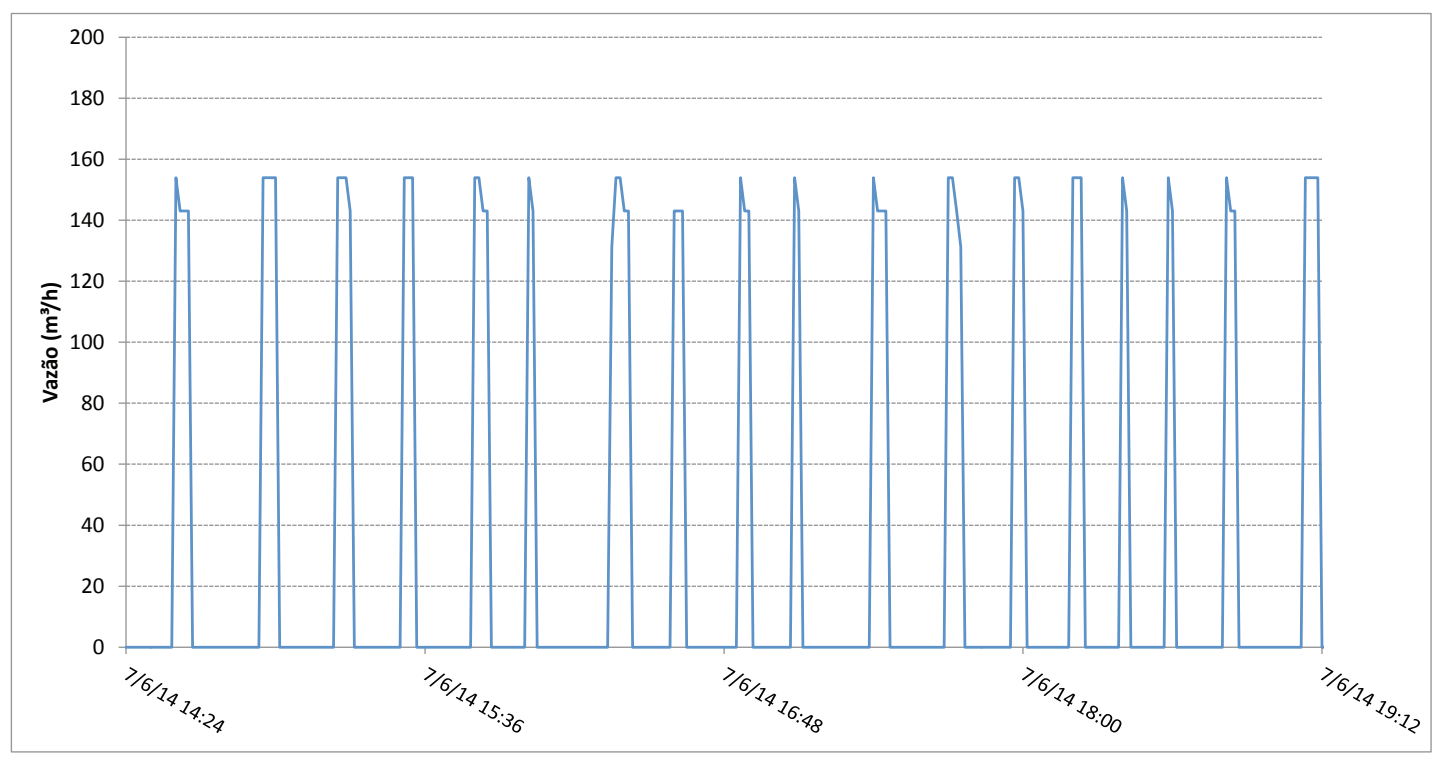

Figura 16 - Esta figura mostra um trecho expandido do gráfico anterior, onde se pode observar a evolução do bombeamento a partir dos sinais do transdutor piezorresistivo. 


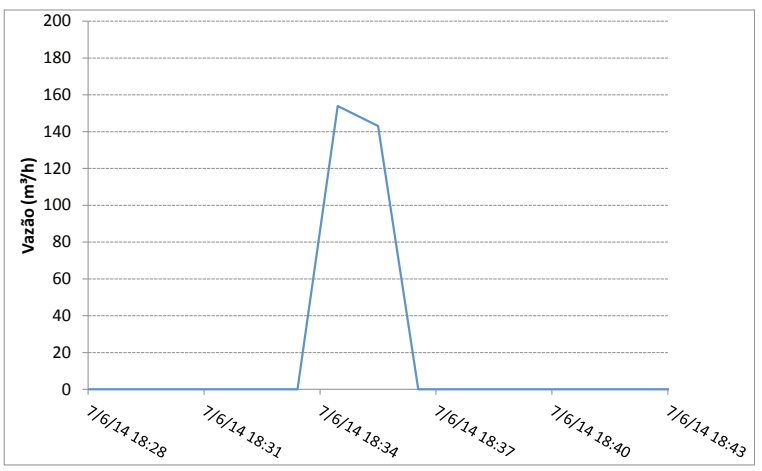

Figura 17 - Sinal de vazão de um ciclo de bombeamento com o uso do transdutor piezorresistivo.

A Figura 17 apresenta o ciclo ocorrido às $18 \mathrm{~h} 30$ com duração de aproximadamente 3 minutos, expandido para mostrar em detalhes o processo de bombeamento. Observar que a vazão atinge um valor máximo, que vai caindo lentamente (pela variação do nível no reservatório de montante, até o desligamento da bomba).

\section{RESULTADOS DAS MEDIÇÕES DE VAZÃO E DE ENERGIA CONSUMIDA COM OTRANSDUTOR CAPACITIVO}

Como mencionado, houve uma pane elétrica do transdutor piezorresistivo, e foi feita então a adaptação de um transdutor de pressão capacitivo convencional ao cotovelo, por meio de uma tubulação especial.

Foram realizados ensaios com a aquisição dos dados de diferença de pressão (para o cálculo de vazão) e das variáveis elétricas (tensão, potência consumida, corrente elétrica). Estes valores foram consolidados e apresentados na Figura 18.

No eixo das ordenadas são apresentados os valores estimados do consumo de energia, e no eixo das abcissas, o tempo de ensaio.
A figura mostra gráficos com os valores de energia consumida obtidos de duas maneiras diferentes.

As curvas na cor verde mostram a estimativa dos valores de energia acumulados e fornecidos a cada 15 minutos, que foi a programação seguida no sistema de aquisição de dados e que coletava as variáveis elétricas. Estas curvas verdes representam a energia consumida pelo sistema inversor/motor/bomba.

As curvas vermelhas mostram a estimativa dos valores de energia consumida pelo sistema motor/bomba, obtidos a partir da curva da bomba levantada em laboratório e inferida a partir dos valores de vazão medidos pelo medidor em teste. Ressalte-se que o sistema de aquisição de dados do IPT coletava informações a cada 10 segundos.

Como se pode ver pelos gráficos, apesar da notável diferença entre os métodos (medição direta da potência versus estimativa da potência a partir da curva da bomba; tempo de coleta de 15 minutos versus 10 segundos; os sistemas de medição partiram em instantes diferentes e foram sincronizados via software), as duas curvas são coincidentes ao longo do tempo.

As diferenças que ocorrem em termos de amplitude necessitam ser melhor estudadas, mas podem representar um elevado consumo de energia em cada partida da bomba e/ou problemas com o travamento parcial do rotor com objetos estranhos, conforme mostra a Figura 19. O próximo passo deverá ser harmonizar o sistema de aquisição de dados de variáveis elétricas e de vazão, sincronizados e com a mesma base de tempo de aquisição de sinais. 


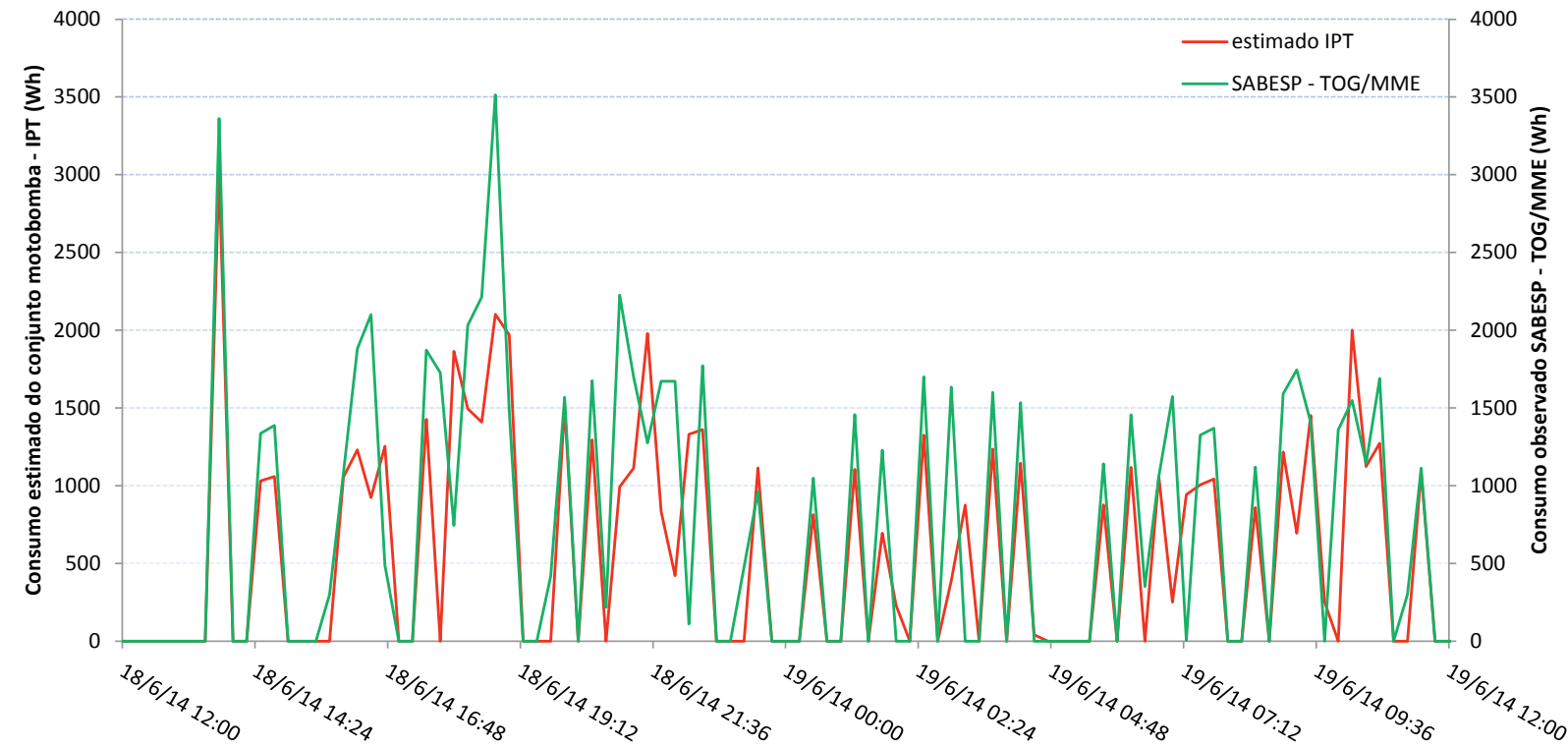

Figura 18 - A curva verde mostra os valores de energia consumida por inversor/motor/bomba, fornecidos pelo sistema de aquisição de dados de variáveis elétricas, acumulados e disponibilizados a cada 15 minutos. A curva vermelha mostra os valores de energia consumida por motor/bomba, estimados a partir da curva da bomba levantada em laboratório e calculada a cada 10 segundos. De 18.06.2014 12h a 19.06.2014 12h.
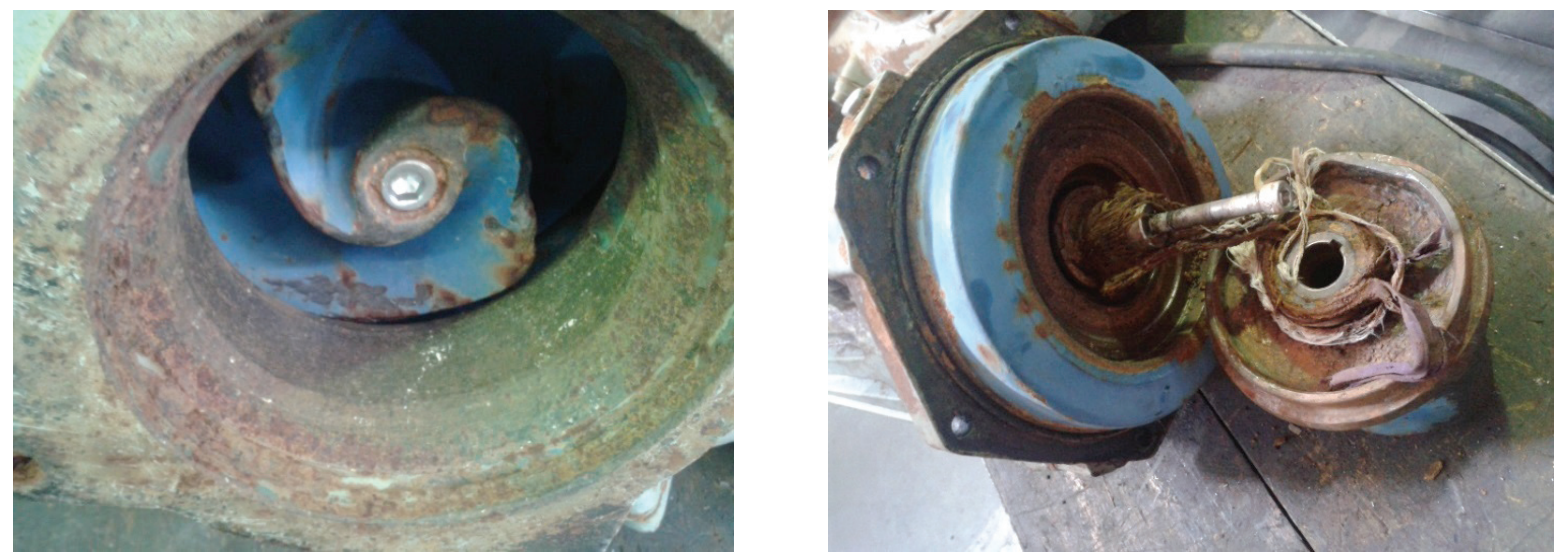

Figura 19. Foto da entrada do rotor e foto do rotor desmontado, onde podem ser vistas cordas e trapos envolvendo o rotor e que podem ocasionar picos de consumo devido a travamentos parciais do rotor.

\section{ANÁLISE DE INCERTEZA DA MEDIÇÃO DE VAZÃO COM O COTOVELO}

A vazão volumétrica através do cotovelo foi determinada por meio da equação 2 , onde foi adicionado um termo, denominado $h_{\text {residual }}$, ao diferencial de pressão $\Delta \mathrm{p}$, para corrigir a diferença de cota vertical entre as tomadas de pressão.

Adicionalmente, uma nova expressão da vazão volumétrica (equação 5), denominada cálculo da vazão "prática", foi utilizada nos ensaios laboratoriais e de campo.

$$
\begin{aligned}
& Q=K \sqrt{\Delta p+h_{\text {residual }}} \quad\left[\frac{m^{3}}{h}\right] \\
& K=K_{34} \frac{\pi}{4} \cdot D^{2} \cdot \sqrt{\frac{2 g}{\rho}} \times 3600 \quad\left[\frac{m^{3} / h}{\left(m H_{2 O}\right)^{0,5}}\right]
\end{aligned}
$$

Onde: 
$\mathrm{Q}$ - vazão volumétrica $\left[\mathrm{m}^{3} / \mathrm{h}\right]$;

$\mathrm{K}$ - coeficiente de vazão "prática" $\left[\frac{m^{3} / h}{\left(m m H_{2 O}\right)^{0,5}}\right]$;

$\mathrm{K}_{34}$ - coeficiente de vazão do cotovelo para tomadas a $45^{\circ}$ [adimensional];

D - Diâmetro interno médio do cotovelo [m];

$\Delta \mathrm{p}$ - diferencial de pressão $\left[\mathrm{mmH}_{2} \mathrm{O}\right]$;

$\mathrm{h}_{\text {residual }}$ - diferença de cota vertical entre as tomadas de pressão $\left[\mathrm{mmH}_{2} \mathrm{O}\right.$;

g - aceleração da gravidade ao nível do mar $\left[9,80665 \mathrm{~m} / \mathrm{s}^{2}\right]$;

$\rho$ - massa específica $\left[\mathrm{kg} / \mathrm{m}^{3}\right]$.

Foi realizada a análise de incerteza da medição de vazão realizada com o cotovelo para avaliar a aderência à aplicação desejada, no caso medição de vazão em estações elevatórias de esgoto.
A equação 5 é o modelo matemático do processo de medição da vazão, e foram utilizadas as recomendações do "Guia para Expressão da Incerteza de Medição"(13) para a modelagem da incerteza, apresentada a seguir.

A incerteza padrão da vazão volumétrica é obtida pela expressão:

$$
u(Q)=\sqrt{\left[\frac{\partial Q}{\partial K} u(K)\right]^{2}+\left[\frac{\partial Q}{\partial \Delta p} u(\Delta p)\right]^{2}+\left[\frac{\partial Q}{\partial h_{\text {residual }}} u\left(h_{\text {residual }}\right)\right]^{2}}
$$

Sendo $\mathrm{u}(\mathrm{K}), \mathrm{u}(\Delta \mathrm{p})$ e $\mathrm{u}\left(\mathrm{h}_{\text {residual }}\right)$ as incertezas padrão do coeficiente de vazão "prática", diferencial de pressão e da diferença de cota, respectivamente, que são, a priori, as fontes de incertezas do modelo adotado. As suas estimativas são apresentadas na Tabela 1.

Tabela 1 - Estimativas das incertezas padrão segundo modelo da equação 5.

\begin{tabular}{|l|l|l|}
\hline \multicolumn{2}{|c|}{ Fonte de incerteza } & \multicolumn{1}{c|}{ Incerteza padrão } \\
\hline $\mathrm{K}$ & 3,247 & $u(K)=\sqrt{\left[\frac{\partial K}{\partial K_{34}} u\left(K_{34}\right)\right]^{2}+\left[\frac{\partial K}{\partial D} u(D)\right]^{2}+\left[\frac{\partial K}{\partial g} u(g)\right]^{2}+\left[\frac{\partial K}{\partial \rho} u(\rho)\right]^{2}}$ \\
\hline $\mathrm{K}_{34}$ & 0,82 & $\mathrm{u}\left(\mathrm{K}_{34}\right)=0,005 \times 0,82$ \\
\hline $\mathrm{D}$ & 0,09995 & $\mathrm{u}(\mathrm{D})=0,0005 / 2$ \\
\hline $\mathrm{g}$ & 9,80665 & $\mathrm{u}(\mathrm{g})=0,02 / 2$ \\
\hline$\rho$ & 998,202 & $\mathrm{u}(\rho)=5 / 2$ \\
\hline$\Delta \mathrm{p}$ & 2500 & $\mathrm{u}(\Delta \mathrm{p})=25$ \\
\hline $\mathrm{h}_{\text {residual }}$ & 102 & $\mathrm{u}\left(\mathrm{h}_{\text {residual }}\right)=25$ \\
\hline
\end{tabular}

Considerando as contribuições das fontes de incertezas apresentadas na Tabela 1 chega-se à incerteza expandida do coeficiente de vazão "prática” $\mathrm{K}$ de $1,4 \%$ e da vazão "prática" $\mathrm{Q}$ de $2 \%$, assumindo um fator de abrangência de $k=2$ e considerando uma probabilidade de abrangência de aproximadamente de $95 \%$.

\section{ESTABELECIMENTO DE ÍNDICE DE EFICIÊNCIA ENERGÉTICA}

Os dados referentes ao período em que se obtiveram medições simultâneas de vazão, utilizando o transdutor capacitivo diferencial, e de energia consumida utilizando o sistema de aquisição de dados de variáveis elétricas, foram tratados para determinar o comportamento do índice de eficiência energética da estação de bombeamento.

Foram, novamente, realizados cálculos para dois tipos distintos de considerações. As figuras seguintes mostram o índice de eficiência energética, calculado pela divisão da energia consumida em $\mathrm{kWh}$ pelo volume de água bombeado, para duas situações:

a energia consumida foi calculada a partir das curvas características da bomba, e representa a energia consumida pelo sistema motor/bomba. A vazão foi calculada a partir dos dados de diferença de pressão medidos pelo transdutor capacitivo e acumulados a cada 10 segundos pelo sistema de aquisição de dados do IPT. Observar que este 
método não leva em consideração os picos de consumo de energia de partida e nem condições de operação reais, com possibilidades de travamentos parciais de rotor por presença de objetos estranhos.

a energia consumida é a indicação da energia acumulada e disponibilizada pelo sistema de aquisição de dados da Sabesp, a cada 15 minutos. A vazão foi calculada a partir dos dados de diferença de pressão medidos pelo transdutor capacitivo e acumulados a cada 10 segundos pelo sistema de aquisição de dados do IPT. A energia consumida neste caso representa a energia consumida pelo sistema inversor/motor/bomba. Observar que este método acumula os picos de consumo de energia de partida e demais condições de operação reais, com possibilidades de travamentos parciais de rotor por presença de objetos estranhos.

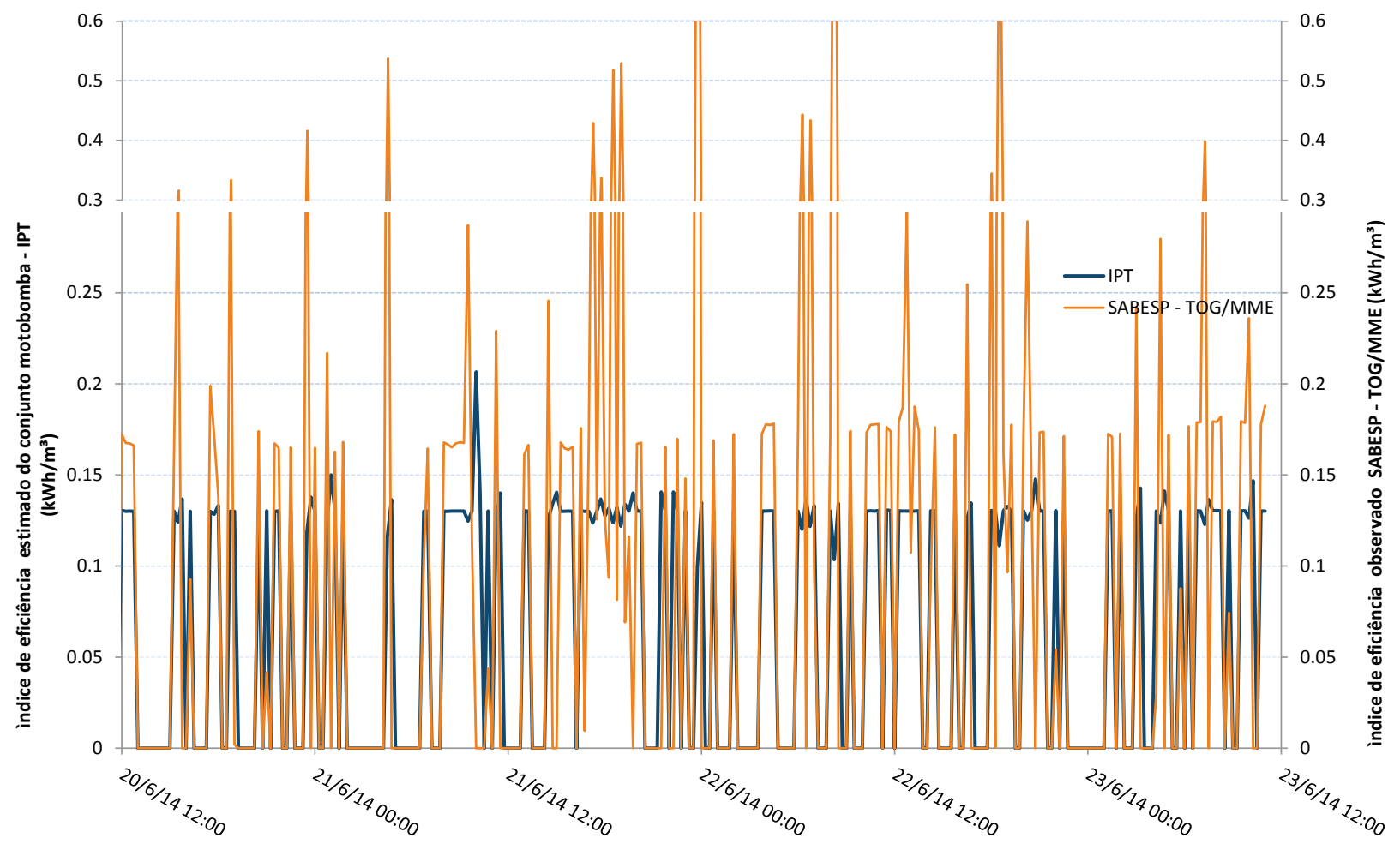

Figura 20 - Índices de eficiência $\left(\mathrm{kW} / \mathrm{m}^{3}\right)$ da unidade de bombeamento monitorada utilizando-se os dados das curvas características das bombas (curva azul, com valores menores) e dados de medição direta da energia via sistema de aquisição de dados da Sabesp (curva marrom).Período de 20.06.2014 12h a 23.06.2014 12h.

Para o uso da Sabesp, o valor que interessa como medida de eficiência energética é o valor médio do índice de eficiência energética. Nos gráficos anteriores, é verificada a existência de um valor médio representado por um patamar para as duas situações:

Para os valores estimados a partir das curvas características da bomba ensaiada, e com valores de vazão medidos a cada 10 segundos, foi obtido:
- $\quad 0,130 \mathrm{kWh} / \mathrm{m}^{3}$ como valor médio para o índice de eficiência.

Para os valores obtidos com medição direta da energia, e com valores de vazão obtidos a cada 10 segundos, foi obtido o valor:

- 0,192 kWh/m³ para o índice de eficiência.

Os índices de eficiência obtidos para valores estimados a partir da curva da bomba são mais es- 
táveis, pois não levam em consideração picos de consumo de energia. Por ser um valor estável, talvez seja indicado para o acompanhamento de longo prazo da queda da eficiência em uma estação.

Já os índices de eficiência obtidos com valores de potência medidos diretamente têm dispersão maior de resultados.

Nos gráficos onde são apresentados os índices calculados a partir dos valores de potência medidos diretamente, vê-se claramente uma flutuação muito grande, sendo provavelmente indicativos de partidas com alto consumo de energia e/ou travamentos do motor com materiais estranhos e, talvez, possa ser um indicativo da qualidade do material bombeado: excesso de picos poderia representar excesso de materiais sólidos entrando no rotor, o que, se for o caso, poderia indicar necessidade de melhor "gradeamento". Mas isso é uma hipótese apenas. Os picos também poderiam representar problemas de excesso de consumo na partida, o que demandaria ação de melhorar o sistema ou então reduzir a vazão para forçar menos partidas e mais tempo em regime permanente.

\section{CONCLUSÕES}

O método de medição de vazão desenvolvido, por meio de um cotovelo, mostrou medições estáveis, repetitivas, e com incerteza muito baixa: para valores de números de Reynolds superiores a $10^{5}$, os valores do coeficiente $\mathrm{K}$ são constantes dentro de $\pm 1 \%$ e seguem a curva teórica dentro de $\pm 0,5 \%$. A incerteza de medição na vazão determinada em laboratório foi de $2 \%$.

Os ensaios de campo, apesar do contratempo da perda do transdutor piezorresistivo, mostraram resultados que indicam possibilidades muito promissoras de análise da qualidade do bombeamento:

- Pode-se definir um índice de eficiência energética para a instalação. Excepcionalmente, no caso destes ensaios, foram obtidos dois índices por conta do processo de aquisição de dados empregado, com tempos de amostragem diferentes para as variáveis de vazão (índice de $\eta_{\text {energética }}=0,130(\mathrm{kWh}) / \mathrm{m}^{3}$ ) e as variáveis elétricas (índice de $\eta_{\text {energética }}=0,192$ $\left.(\mathrm{kWh}) / \mathrm{m}^{3}\right)$. Novos ensaios deverão ser realizados, desta vez com tempos de amostragem idênticos para as variáveis, e esta questão poderá ser resolvida.

- Para efetuar comparação entre índices de eficiência energética de estações de bombeamento distintas, deve-se de alguma forma parametrizar o índice, por exemplo, multiplicando-o por $\mathrm{d} / 10$, onde $\mathrm{d}$ seria a diferença de cotas entre o nível de montante e o de jusante, e 10 seriam 10 metros genéricos de cota. Desta forma, estações de bombeamento com diferenças de cotas elevadas não seriam penalizadas com eficiências menores, devido ao gasto de energia apenas para elevação.

- Picos de consumo podem ser observados nos gráficos e imediatamente verificados. Podem ser identificados problemas elétricos de partida, travamentos do rotor com material estranho, etc.

- No caso da estação que foi ensaiada, a bomba utilizada provavelmente não é a melhor escolha: o processo era muito intermitente, o que certamente ocasionaria problemas de manutenção e operação fora do BEP (Best Efficiency Point). Uma bomba de porte menor, com funcionamento mais contínuo, sem tanta intermitência, e funcionando próxima ao BEP, representaria uma escolha melhor do ponto de vista do consumo energético e do desgaste do conjunto motor-bomba.

Estas observações indicam que a análise de um índice de eficiência energética de uma estação de bombeamento pode fornecer pistas muito interessantes sobre a qualidade do bombeamento, problemas que possam afetar a bomba, degrada- 
ção das condições de operação e problemas de manutenção. Tudo isso possibilitado pela medição de vazão com este dispositivo tipo cotovelo.

\section{O próximo passo deverá ser investigar como se po-} deriam estabelecer os limites de utilização destes medidores, estudando-os em bancada para determinar sua dependência de diâmetros, rugosidade, números de Reynolds, perturbações na área de medição e condições geométricas das tomadas de pressão, exatamente como se fez durante mais de 80 anos com placas de orifício e Venturis. Devese também avançar na definição de um índice de eficiência energética capaz de cobrir pelo menos uma família de estações de bombeamento.

\section{REFERÊNCIAS}

Addison, $\mathrm{H}$. The use of pipe bends as flow meters. Engineering, p.227, Mar., 1938

Baratto, Antonio Carlos (Coord.). Avaliação de dados de medição: guia para a expressão de incerteza de medição; tradução da $1^{\text {a }}$ edição de 2008 da publicação JCGM 100: 2008 Evaluation of measurement data: guide to the expression of uncertainty in measurement. Disponivel em: <http://www.inmetro.gov.br/ noticias/conteudo/iso_gum_versao_site.pdf>. Acessado em set. 2014.

Hauptmann, E.G. Take a second look at elbow meters for flow monitoring. Instruments and control systems, p. 47-50, Oct., 1978.
Howe, W.H., Lipták, B.G., Gibson, I.H. Elbow taps. In: LIPTÁK, B.G. (Ed.) Flow measurement. Pennsylvania: Chilton Book Co, 1993. Chap. 2.6.

Isaacs, W.P. Measurement of slurry flow by use of 90 degree elbow meter. Leigh University, Fritz Engineering Laboratory, 1964. (Report no 299.1).

Lansford, W.M.. The use of an elbow in a pipe line for determining the rate of flow in the pipe. University of Illinois Bulletin, vol XXXIV, n 33, 22 dezembro, 1936.

Levin, A.M. A flow metering apparatus. American Society of Mechanical Engineers, Paper n. 1436, Spring Meeting, St Paul-Minneapolis, June 1914.

LIPTÁK, B.G. (Ed.) Instrument engineers' handbook. 4th ed. NewYork: CRCPress, 2003. v. 1: Process measurement and analysis.

Murdock, J.W.; Foltz, C.J.; Gregory, C. Performance characteristics of elbow flowmeters. Transactions of the ASME, Sept., 1964.

Taylor, D.C.; McPherson, M.B. Elbow meter performance. Journal AWWA. Nov., 1954

Warhaft, Z. Turbulence in nature and in the laboratory. PNAS, v.99, suppl.1, p. 2481-2486, Feb., 2002. Disponível em: <http://www. pnas.org/content/99/suppl_1/2481.full.pdf+html>. Acessado em set., 2014.

Yarnell, D.L. Flow of water through 6 inch pipe flows. Washington: USGS, 1937. (Technical Bulletin no 577)

Yuan, B.Z. et al. Hydraulic design procedure for bypass flow meters using a pipe bend. Transactions of the ASAE, v.46, n.2, p. 279285, 2003. 